\title{
Task-Based Teaching Method and Its Application in the Research of Teaching of Reading Practice
}

\author{
Liu Jia ${ }^{1,2}$, Zhou Bo Bo $^{2,3}$ \\ ${ }^{1}$ Chengdu Sport University, ${ }^{2}$ Palacky University ${ }^{3}$ Sichuan Normal University
}

Key words: high school teaching; Task-based teaching mode; Multiple intelligences theory Abstract: In the classroom teaching, the knowledge cramming teaching mode is boring. And the task-based teaching activities emphasize that the students should "learn by doing", and the teachers should design specific and actionable tasks based on the classroom activities. In this way, the students could complete the tasks through perception, experience, practice, participation and cooperation form etc. to achieve the purpose of the study and master the knowledge. Thus, it would enhance students' interest and confidence in learning, and make it easier for them to achieve autonomous learning and improve their ability to use language for communication. The author of this paper combines multiple intelligence theory with task-based teaching mode, hoping through researches to found the problems in teaching by reading. Besides, the author puts forward the ways of exploring the best teaching mode in English reading teaching practice. And the author insists that we should cultivate the students' abilities in many aspects through rich teaching activities.

\section{Researches Related to the Task-based Teaching Mode}

Along with the deepening of education reform in China, in domestic, people are also gradually paying attention to the study of the task-based teaching mode. Besides, based on the practical situation in Chinese education, they have put forward a series of educational teaching ideas and education patterns that are suitable for the development of the domestic education.

The Task-based Teaching Mode. "Task-based teaching mode” means that the teachers put the tasks into the classroom activities, and teach with task organization. Therefore, the students could complete these tasks by participating in the activities, thus achieve the goal of learning and mastering language. Task is the key goal. Whether the designing task carries any significance is the key to a successful lesson. In the "task-based teaching mode", the "tasks" can be divided into three categories, in which, one takes the teachers as the leaders. And this category takes achieving the final communication as the ultimate goal. One is mainly carried out by the students, namely, the students are taken as the main body of classroom practice activities. One is related to scenarios, namely, the related topics are given priority to carry out activities by using target language.

Present Situation of Researches of Task-based Teaching Method at Abroad. Prabhu (1987) put forward the teaching method that takes the students as practitioners, in which, the tasks are designed based on classroom activities, and finally, the students complete the language learning by doing activities. In language learning process, this method pays more attention to the cultivation of language ability, not just the language itself.The defects of Prabhu's teaching mode design, however, are also more obvious, for example, there is no rigid rule to guide the choosing of tasks, and the arrangement seems to be too random, and there is no document about the difficult degree of the tasks and so on. Therefore, Willis (1993) put forward that it is quite important for the teachers to choose the tasks that are of moderate difficulty, in this way, it could be easier for them to arouse the 
enthusiasm of students, and thus to improve the classroom efficiency. In 1996, Willis expanded the Prabhu theory. Besides, he summarized the task-based learning mode into three phases, namely pre-task, in-task and language focus. The advantage of the task-based learning mode is that the language is used in the process of the real application in the actual communication.

After entering the new century, a large number of experts and scholars have put the task-based language teaching mode into teaching practice after having studied it. And they have obtained good results and achieved fruitful research theory. Lu Ziwen (2002) points out that classroom knowledge of task-based mode should include three aspects: import part of teaching content, explaining level of language knowledge, and cultural information in the final render phase. The task-based teaching theories of Gong Yafu and Luo Shaoqian (2006) not only take the law of language acquisition and curriculum reform theories as a foundation, at the same time, these theories also cut basic theories in psychology and pedagogy into this field. Liu Jiajun and Xu Piqing (2005) used the network environment as the carrier, and they carried on task-based classroom teaching experiment in university English, and have achieved good teaching effect. XingFeng (2007), the chief editor of Task-based Teaching Researches Used in English Teaching in Ordinary High Schools, worked together with many other scholars on task-based teaching mode used in English class under the background of new curriculum.

\section{Task-based Teaching Mode of English Reading}

Teaching activities of task-based reading are divided into three stages:

Pre- reading Stage. In pre-reading stage, the teachers, through introducing related background knowledge of reading material to students, stimulate students' reading desire. In this stage, the teachers can set up some tasks, in this way to require student complete the task in a variety of forms such as communication and looking up materials. And the teachers should enable every student to participate in these activities to achieve resource sharing, also make them prepared for the next reading.

While-reading Stage. In while-reading stage, the students, under the teacher's guidance, carry out discussion step by step, and fully understand the content and structure of passages. Besides, through different task activities, the teachers could stimulate students' interest in actively participating in getting information, and further digesting reading materials, and developing their reading ability.

Post-reading Stage. The important purpose of post-reading stage lies in consolidating the knowledge learned. Teachers can arrange the study group or individuals to present their task achievements through class performance in the class and communications after class, and other forms, in this way to develop students' thinking ability.

The Application of Multiple Intelligences Theory in Task-based Reading Mode in High School English Teaching.

The Necessity of the Application of Multiple Intelligences Theory in Task-based Reading Mode in High School English Teaching.

1. The Application of Multiple Intelligence Theory Conforms to the Needs of Current English Teaching Reform in High School . After the theory of multiple intelligences was introduced in domestic, for it contains abundant education ideas, the domestic experts quickly combined it with teaching practice, and made researches. The obvious feature of present English language used in high school lies in that the language application is unbalanced in every aspect. However, the eight kinds of intelligences in multiple intelligences theory directly covered $r$ all the skills trainings that the language learners should master. Therefore, multiple intelligences are widely used in the process 
of English reading teaching. Compared with traditional teaching mode, the teaching mode that guided by multiple intelligences theory is more scientific, rationalization, and more in line with the New Curriculum Standard's needs of teaching reform.

2. Dilemma of Task-based Mode Exists in English Reading Teaching in High School. Based on teaching practice, the author find that although the task-based teaching method is the teaching method strongly recommended by English Course Standard, due to various factors, there are still many difficulties in current task-based English reading teaching of high school: (1) The lagging of education concept among teachers. Reading education, which is to cultivate students' reading ability. However, in the process of task based reading teaching, teachers still take knowledge as the center, and the reading materials as an important form of teaching knowledge. It is mainly manifested in the classroom teaching practice still to teachers as the center, with vocabulary, language evaluation as the main line, and will complete the reading material decomposition for isolated language teaching task, ignore the basic ideas and information contained in the reading material, weaken the basic functions of English reading materials, neglect on Cultivation of student's reading skills and reading ability. (2) Teachers' training modes are unitary. Although task-based reading teaching methods varied, but the teacher in the practice process of master many teaching mode and its effective application to teaching practice is extremely difficult, and task-based reading teaching as a new teaching mode is really effective to improve the students' reading can force still has doubt, relatively simple question and answer teaching usually become the present English reading teaching process teachers were most willing to adopt the method. This also led to the task of English teachers is part of the teaching design is too monotonous. In this monotonous teaching mode, teachers tend to prepare questions in the teaching design, and ask students to ask questions, students always in a passive position, is not conducive to the initiative of students learning and divergent thinking. At the same time, because of the students' understanding of reading materials is limited, often stay in the surface of the reading materials, can not grasp the context of the article, and then affect the accuracy of reading comprehension. In addition, a single training mode also with the current development trend of high school English reading teaching material diversification does not match. (3) The students' reading skills are monotonous. In task based English reading teaching mode, teachers often arrange related issues, so that students with the task of learning. But most of the teachers will ask students to word of the article and scrutiny, did not miss any difficulty. But in the actual test once the strange words, students often appear to panic phenomenon, to give up the overall meaning of the article, and the time spent on the details of the individual words in the location of the. Therefore, reading in the task-based teaching process, teachers should also teach students to master basic word reading skills. (4) The students' reading habits are poor. In the task-based reading teaching mode, teachers advocate students extracurricular reading materials, such as English newspapers, magazines, books and so on, not only can accumulate vocabulary, sentence structure, can also expand their knowledge, cultivate a sense of English language, effectively improve the students' reading ability. But the vast majority of students are often only to complete the task, the nature of reading task behind, lack of good reading habits. Due to the fact that there are many problems in the English reading teaching of current high schools, although the teachers and students spend a lot of time and effort in English reading, it is still difficult for students comprehend English reading materials. The above situation requests us to find the teaching mode that is more appropriate as soon as possible. Besides, we should change the current reading teaching thoughts. Through a series of teaching practice, we should search for a more valuable reading teaching mode. 
3. The ApplicationMethods of Multiple Intelligences Theory in the Task-based Mode of High School English Reading Teaching

1. Language Intelligence and Its Applications. Language and language intelligence are closely linked to each other. Since people made the language, the human communication became more and more frequent, and language intelligence arose at the same time. The high school phase is the period in which human psychology, physiology and language experience the most rapidly growing changes. Besides, with the advancement of age and enhancement of cultural level, people's language level is going through constant change. It would carry vital significance in English reading teaching if the teachers create a good language environment for students. (1) Reading teaching model. The current English reform attaches great importance to the development of students' comprehensive ability, and the development of ability takes basic knowledge as premise. Reading exactly could cultivate students' language sense, and deepen their understanding and memory, which could provide language accumulation for the improvement of reading ability. Therefore, the teachers should flexibly use the reading teaching mode, and in this way to improve students' reading ability. (2) Story teaching mode. Story teaching mode is traditional teaching method. If we apply this mode to the teaching process of English reading, we could enhance the students' exchange of emotions and accumulation of knowledge while enhance their English spoken ability. Teachers of English can weave a story with English teaching goal, basic knowledge and comprehensive skills in it. Roles in the story can be carried out among teachers and students. The role acting not only can be put before the English class, as a warm-up, but also can be put before the class is over, as a review of this class. In the teaching process, the story teaching mode, for the teachers of English, could make English learning atmosphere in the classroom be more active while promoting students' interest in learning and mobilizing their participation and enthusiasm. Besides, in the teaching process of English reading, group learning, live interview, debate competition and so on can enhance students' language level.

4. Mathematical Logic Intelligence and Its Application. Mathematical logic intelligence consists of logical thinking ability and logical reasoning ability. The teachers could tune the mathematical logic intelligence into the teaching of English reading, and in this way guide students to solve problems by predicting, reasoning and other methods, and to stimulate their initiative. (1) Question teaching mode. American scholar Nunan argues that, in the process of second language learning, the effective questions and class teaching organization could greatly help the classroom teaching and language acquisition. In the teaching process of reading, only by incessant questions, the teachers could know the student's understanding degree of discourse. In the process of design questions, for the teachers, they must base on the teaching goal, teaching tasks, teaching contents and teaching object to design questions with certain purposes. Besides, the teachers should fully grasp the different questions timings, difficult degrees and quantity proportion. (2) Reasoning teaching mode. In the process of English teaching, reasoning mainly refers to the teachers' guidance of students to link the article content with real life, and to guess the author's attitude and writing intention according to the literal meaning of the materials. In addition, in the teaching process of English reading, the application of calculation method, debate method, sorting method and so on are conducive to improve students' logic thinking ability.

5. Visual Spatial Intelligence and Its Application. Foreign scholars have made tests, and from which they finally found that compared texts with images, images are more likely to leave a person deep impression. Therefore, the teachers can convert the reading texts into the form of a chart to show the article content. Through stimulating students' vision, the teachers can help the students form a smooth structure, and deepen their memory, so as to achieve the aim of improving the 
efficiency of teaching and learning. (1) Imagination teaching mode. Imagination is the most valuable ability. Imagination mainly refers to the imagination happened in the process of reading English material, for the students, the concepts association with specific English words and statements. For example, My First Day at Senior High in the first book-The Research Version of Compulsory High School English, the teachers can let the students recall their English classes in the junior middle school, and under the guidance of teachers, and then let them understand the basic characteristics of English reading classes in Senior High school stage. However, in traditional classroom education, the critical words, as "sit up”, “keep quiet”, and “... talk too much” will severely hinder the students' imagination. In the long term, the students only respect the rules, and would give up imagination and thinking. (2) Appreciative education mode. In the classroom, the teachers use multimedia and other teaching modes intuitively, and deeply present English reading materials in front of the students, in this way to stimulate students' visual spatial intelligence. Take A master of nonverbal humor in grade four of the new compulsory standard English for high schools as an example, the teacher is unable to explain the superb performance of Charlie Chaplin simply through language. If the teachers play in advance related films, the students could have a general idea of the English plots. Also it could make them easier to roughly understand the context and language structure of this article.In addition, graphic method, color tag method, thinking inspiration method and so on, these displaying teaching modes can be used to improve the students' visual spatial intelligence, and improve the efficiency of reading teaching of English.

6. Body movement intelligence and Application. Body movement intelligence mainly refers to the ability to express thoughts and feelings and to solve problems by using movement and expression". According to the relevant experts, in people's daily communication process, the non language communication tool to transfer the information to reach five to six. American scholar Turtledove through a long time survey found that in the whole process of learning, the knowledge gained through the body movements occupy about 70\%. Therefore, teachers should consideration of non language communication in the process of teaching practice, help students to understand the English national body expression of specific connotation, and students are encouraged to take appropriate action expression to participate in the body in the process of communication.In real life, students often have strong physical intelligent quick reaction, expression of desire, strong practical ability and good advantage. In the traditional teaching model, teachers for classroom activities subject, students just passively accept knowledge, weak interaction. But the concept of new curriculum standard should be the core content of classroom practice to improve the students' comprehensive quality. Therefore, teachers should make use of gestures, expressions, body movements to create a good learning atmosphere, so that students in a relaxed learning environment to move up.

7. Music intelligence and Application. Zhu Li, a domestic scholar, has studied music to promote the second language acquisition. Music music can not only promote the learner's comprehension, strengthen sense of rhythm, can also increase the vocabulary, language awareness, stimulate the learners learning English enthusiasm "[Li Dong Zhu. Multiple intelligence theory in senior middle school English teaching application [J]. Teaching exploration, 2007 (3)". High school students are more sensitive to hearing, good at expression. Teachers in English class is an appropriate use of music to improve students' English learning initiative, to help students grasp the music rhythm, intonation, rhythm and tone, improve students' musical intelligence.

8. Interpersonal intelligence and Application. Interpersonal skills may be the essence of human nature, which is one of the most creative individuals to maintain the human society, one of the most creative. Understanding, far sighted, to take into account the consequences of their actions bring to 
others, and successfully dealing with the surrounding various relationships [Chen Li. Characteristics of the development of children's interpersonal intelligence and culture.2002.6.] [J]. Early education. In the author's opinion, English classroom practice is teacher-student and student student interaction and mutual influence process, so teachers can build a good interpersonal environment, use of group learning and brainstorming and other learning strategies to improve the efficiency of the English school, the development of students' social skills.

9.With the application of intelligent self introspection. Self reflection ability strong person can correctly recognize their own advantages and disadvantages, and self motivation, reflect on their own ideas and practices. Teachers in the process of English teaching, self introspection function used by the students to help students in-depth understanding of the, and personalized reading, and in the process setting guide the students to reflect on, so as to improve the efficiency of reading. The new English curriculum standard requires teachers to change the traditional teaching mode, and constantly reflect on the teaching process, to find the advantages and disadvantages, and to clear the direction .

10.Natural observation intelligence and its application. "Nature is the world's most interesting teacher." [Kyushu spring. Children go out [J] management at home and abroad.2010.4.]. Man and nature should be integrated, the nature is attracting the curiosity in different poses and with different expressions of high school students. Teachers should constantly guide students into nature, develop intelligence, participation and natural activities related to teaching methods, and provide the real world outside of the classroom for students to contact each other. In the reading teaching process, teachers should encourage the students out of the classroom, edify sentiment, to observe the nature of English learning and the integration of objective.

\section{Conclusion}

At present, the new education ideas and teaching modes update very quickly, thus the teachers' comprehensive qualities play a key role to improve the effect of classroom teaching and curriculum reform. Despite abundant professional knowledge and basic skills, the new curriculum reform requires that the teachers must have a good knowledge reserves, and should innovate teaching modes incessantly. Excellent English teachers should constantly reflect on their teaching effect, and look at their own knowledge reserves. Besides, they should set up the concept of lifelong learning, and constantly broaden their knowledge, and enrich their own culture understanding. Of course, the teachers should use modern teaching technology and innovative teaching thinking constantly in the process of teaching. And they should communicate with colleagues about teaching now and then.

\section{References}

[1] Cheng Xiaotang Lu Ziwen, Zhong Shumei. The Application of Task-based Language Teaching Mode in English Teaching[J]. Journal of Foreign Language Institute of Shandong Normal University(Basic English Education), 2007, 06: 3-8.

[2] Gu Ting. The Application of Task-based Language Teaching Mode in Primary Teaching, in which the Chinese is taken as a Foreign Language[D]. Beijing Language and Culture University, 2006.

[3] FengYuFang, Tang Xiaoyan. The Application of Task-based Language Teaching Mode in English Teaching[J]. Foreign Language and Foreign Language Teaching, 2004, 06: 35-38. 
[4] Lu Ziwen. Brief Introduction of Task-based English Teaching Mode[J]. Subject Education, 2002, 06: 26-30.

[5] Wang Jing. The Design and Practice of Task-oriented Interpretation Teaching Mode under the Network Environment[J]. Audiovisual Education of Foreign Language, 2010, 03:34-37.

[6] Yu Zebiao. Current Situation of Task-based Teaching Mode[J]. Journal of Chongqing Teachers’ College, 2001, 02:54-58. 